\title{
Modulation of the Kara Sea Ice Variation on the Ice Freeze-Up Time in Lake Qinghai
}

\author{
YONG LIU \\ Nansen-Zhu International Research Centre, Institute of Atmospheric Physics, Chinese Academy of Sciences, and \\ University of Chinese Academy of Sciences, Beijing, China \\ Huopo Chen, HuiJun Wang, And JiAnqi Sun \\ Nansen-Zhu International Research Centre, Institute of Atmospheric Physics, Chinese Academy of Sciences, \\ Beijing, Joint Laboratory of Climate and Environment Change, Chengdu University of Information Technology, \\ Chengdu, and Collaborative Innovation Center on Forecast and Evaluation of Meteorological Disasters, \\ Nanjing University for Information Science and Technology, Nanjing, China
}

HUA LI

Nansen-Zhu International Research Centre, Institute of Atmospheric Physics, Chinese Academy of Sciences, and University of Chinese Academy of Sciences, Beijing, China

\section{YuBAO QIU}

Digital Earth Laboratory, Institute of Remote Sensing and Digital Earth, Chinese Academy of Sciences, Beijing, China

(Manuscript received 24 September 2018, in final form 11 February 2019)

\begin{abstract}
Lake ice phenology, as an indicator for climate variability and change, exerts a great influence on regional climate and hydrometeorology. In this study, the changing characteristics of lake ice phenology at Lake Qinghai (LQH) are investigated using retrieved historical datasets during 1979-2016. The results show that the variation of the lake freeze-up date over LQH is characterized by a strong interannual variability. Further analysis has revealed that November sea ice concentration (SIC) variation in the Kara Sea can exert a great impact on the freeze-up date at LQH. During the low sea ice years, the open sea serves as a strong diabatic heating source, largely contributing to the enhanced Arctic Eliassen-Palmer flux, which then results in the deceleration of zonal wind in the middle and high latitudes. In addition to this, accompanied with the decreasing Kara SIC, the enhanced stationary Rossby wave flux propagating along the high-latitude regions may further exert remarkable influences in deepening the East Asian trough, which provides a favorable atmospheric circulation pattern for cold air intrusion from the Arctic and Siberian regions to mainland China. The decreased surface air temperature would thus advance the freezing date over LQH. Furthermore, the close relationship between atmospheric circulation anomalies and Kara SIC variations is validated by a large ensemble of simulations from the Community Earth System Model, and the atmospheric circulation patterns induced by the SIC anomalies are reproduced to some extent. Therefore, the November Kara Sea ice anomaly might be an important predictor for the variation in the freeze-up date at LQH.
\end{abstract}

\section{Introduction}

Lake Qinghai (LQH), located in the northeast margin of the Tibetan Plateau (TP), is the largest inland lake in China (Fig. 1). The lake is a terminal, slightly saline lake with no surface water outflow, and it has an area of

Corresponding author: Chen Huopo, chenhuopo@mail.iap.ac.cn approximately $4318 \mathrm{~km}^{2}$, at an altitude of over $3000 \mathrm{~m}$ (Zhao et al. 2017). Because of its unique geographical location, LQH plays an important role in the surrounding semiarid ecosystem, hydrometeorology, and regional climate in the northeastern TP (Dong et al. 2018; Wang et al. 2014; Zhao et al. 2017; Zhu et al. 2018). For example, the desertification in the lake beach area, loss of grazing grassland around the lake, and deterioration of the water 
(a)

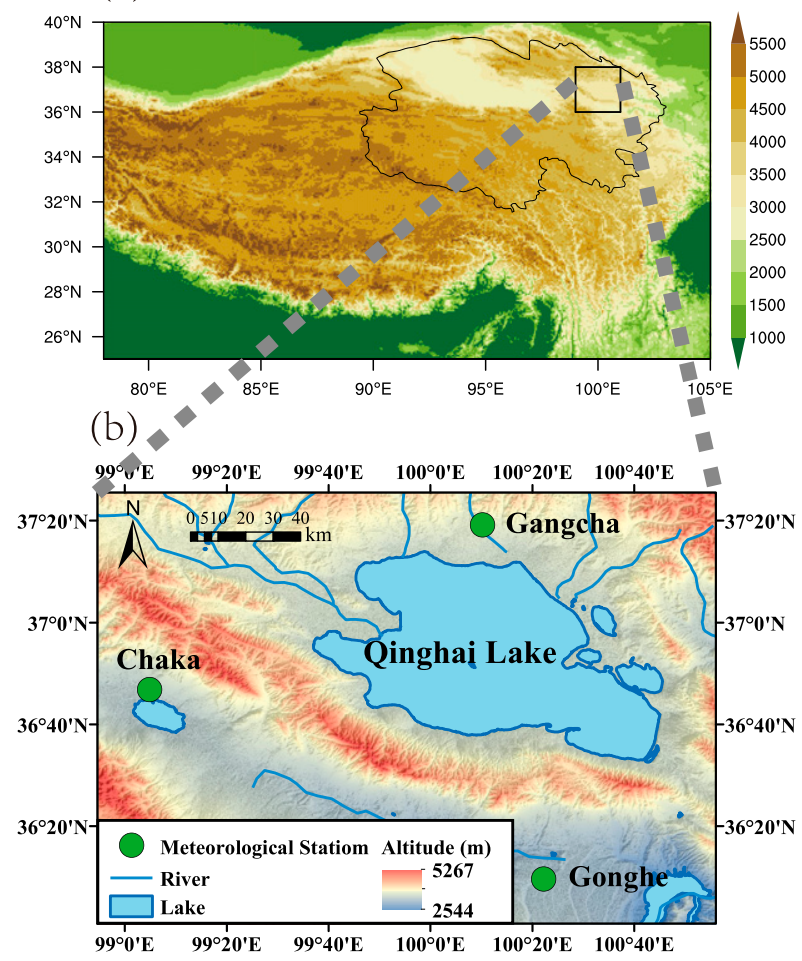

FIG. 1. Location maps of Lake Qinghai and three meteorological stations that are used in this study.

quality are closely associated with the decrease in the water level of LQH (Qin and Huang 1998). A recent study has suggested that the TP lakes processes can exert great influence on mesoscale precipitation and regional-scale circulation by changing the surface heat flux (Zhu et al. 2018). In addition, lake groups in the TP are rarely affected by human activity directly; to some extent, lake ice phenology characteristics can reflect the regional climate change in the natural state. Therefore, it is of great significance to study hydrometeorology and cryosphere over $\mathrm{LQH}$ and the TP for lake management.

The atmospheric circulation patterns over the TP are characterized by the interaction of the East Asian monsoon, the Indian monsoon, and the westerly jet stream, leading the TP to be one of the most sensitive regions to climate change around the world (Zhang et al. 2011). However, the harsh meteorological conditions and steep terrain make it difficult to understand the recent climate over the TP in response to the global warming. Hence, satellite remote sensing provides a powerful and credible tool to monitor climate change in the high mountains (e.g., Cai et al. 2017; Guo et al. 2018; Zhang et al. 2011). Although there is no explicit and integrated method to depict the climate over the TP, the variations in the climate of this area can be reflected by several cryosphere indicators. For example, some studies have highlighted the roles of changes in the snow depth, glacier extent, and lake ice phenology in climate changes over the High Asian regions in recent decades (Xu et al. 2017; You et al. 2011; Yao et al. 2012; Yao et al. 2016). More importantly, previous studies have indicated that the lake ice phenology can be indicated as a clear and direct indicator of climate variability, and in some cases it is more robust than temperature in monitoring the climate (e.g., Latifovic and Pouliot 2007; Livingstone 1997; Robertson et al. 1992).

Prior to the current study, numerous studies have focused on the variations of lake ice phenology in the TP relating to regional meteorological elements (Ke et al. 2013; Yao et al. 2016). In general, the regional surface air temperature can play a dominant role in the variations in lake ice phenology (e.g., Wang et al. 2017). Some previous studies (e.g., You et al. 2010) have found that the high altitude, complex terrain, and regional atmospheric circulation anomalies also exert great influences on the lake ice freeze-up periods in the TP. In addition to this, some studies have indicated that the response of the lake ice phenology to climate change in the TP is generally related to warming around the TP (Cai et al. 2017; Ke et al. 2013; Yao et al. 2016). Also, mounting evidence suggests that the warming in the TP is closely associated with atmospheric circulation anomalies and external forcing factors (e.g., Rangwala et al. 2009; You et al. 2010). For example, some recent studies have documented that the weakening of the winter monsoon can be seen as a major factor that accounts for the climate warming experienced in the northern TP, which is typically accompanied by changes in midlatitude atmospheric circulations (e.g., You et al. 2010). Moreover, some studies (e.g., Rangwala et al. 2009) have argued that the increases in surface water vapor and the related changes in downward longwave radiation appear to be partly responsible for the prominent winter warming trend in the TP. Additionally, large-scale circulation teleconnections have also been indicated as major contributors to the southern TP climate. For example, some studies have suggested that the North Atlantic Oscillation (NAO) can exert a significant impact on the East Asian winter climate via stimulating quasi-stationary Rossby waves along the North Africa-Asia jet waveguide (e.g., Watanabe 2004; Zuo et al. 2016). Xin et al. (2010) have also presented evidence that the changes in the winter NAO are connected to the adjustment of the atmospheric circulation anomalies over the TP. However, the effect of atmospheric stationary wave patterns characterizing the midlatitude climate regime at $\mathrm{LQH}$ remains unclear, such as how $\mathrm{LQH}$ responds to the socalled Silk Road pattern and circumglobal teleconnection 
pattern (Chen and Huang 2012). Hence, the ambiguous recognition of climate change responses over the northern TP suggests more studies are needed regarding this aspect.

As mentioned above, the climate in the northern TP is closely associated with the changes in midlatitude atmospheric circulation anomalies. Recently, an increasing number of studies have found that Arctic sea ice loss has significantly affected midlatitude atmospheric circulation and weather patterns by regulating the heat exchange between the ocean and atmosphere ( $\mathrm{He}$ et al. 2018; $\mathrm{Li}$ et al. 2015; Li et al. 2018; Liu et al. 2012; Song et al. 2012; Wang et al. 2015; Wang and Chen 2016; Wang and Liu 2016). For example, Liu et al. (2012) have showed that autumn Arctic sea ice variation is closely linked to changes in large-scale circulation in the middle and high latitudes, with some resemblance to the negative phase of the winter Arctic Oscillation, but one clear difference is that there is an increasing meridional meander in the midlatitudes during the low sea ice years. Outten and Esau (2012) have also indicated that the weakness of wintertime westerly winds over the midlatitude regime, which partly results from a decreased meridional temperature gradient related to sea ice variation around the Kara Sea, can lower the temperatures in Eurasia. Briefly, the variation of Arctic sea ice can exert significant impacts on local and remote weather and climate conditions at the middle and high latitudes (Kug et al. 2015; Vihma 2014). Hence, it makes sense to take into consideration the linkage between Arctic sea ice variation and lake ice phenology over the TP. On the basis of the above studies, we also find a close relationship between the variations of winter Kara Sea ice cover and the lake ice freeze-up date at LQH from the perspective of statistics. However, how the variation of Kara Sea ice influences the lake ice phenology at LQH remains unclear, which is the main topic of this study.

The aim of this study is to explore the possible mechanism for the variations of the lake ice phenology over LQH. This paper is arranged as follows. Section 2 presents a brief description of the data and methods. In section 3 , the main results are provided, including the analysis of the lake ice phenological characteristics and explanations of the impact from Kara Sea ice. Finally, a discussion and conclusions are presented in section 4 .

\section{Data and method}

\section{a. Dataset}

The lake ice phenology dataset used here is obtained from the satellite-retrieved data developed by Cai et al. (2017). More detailed information about the method of extracting the lake ice phenology data is accessible in the paper published in Science of the Total Environment by Cai et al. (2017). Furthermore, as indicated by the National Snow and Ice Data Center (NSIDC), the freeze date is defined as the first date on which the water body was observed to be initially ice-covered, and the breakup date is defined as the date of observed ice-free conditions before the summer open water phase. The ice duration is thus the number of days that a lake body is covered with ice. Hence, we selected the freeze starting date (ablation completion date) as the freeze date (break-up date).

The site-observed daily temperature, precipitation, and surface wind velocity datasets around the LQH regions, including Gangcha, Gonghe, and Chaka, are provided by the National Climate Center, in the China Meteorological Administration. The monthly Arctic sea ice concentration (SIC) dataset is derived from the Hadley Centre Sea Ice and Sea Surface Temperature dataset, version 1 (HadISST1), with a resolution of $1.0^{\circ} \times 1.0^{\circ}$ (Rayner et al. 2003). The European Centre for Medium-Range Weather Forecasts (ECMWF) interim reanalysis (ERA-Interim) monthly data with a horizontal resolution of $0.75^{\circ} \times 0.75^{\circ}$, including sea level pressure, 2-m temperature, near-surface wind, geopotential height, and high-level winds, are used (Dee et al. 2011). In addition, we also use the monthly mean data from the National Centers for Environment Prediction (NCEP)-National Center for Atmospheric Research (NCAR) analysis (Kalnay et al. 1996), with a configuration of $2.5^{\circ} \times 2.5^{\circ}$ horizontal resolution and 17 vertical pressure levels extending from 1000 to $10 \mathrm{hPa}$.

Large ensemble simulations from the Community Earth System Model version 1 (CESM-LE) are also employed for the validation analysis in this study (Kay et al. 2015). There are 40-member ensembles included in CESM-LE, with a horizontal resolution of $0.9^{\circ} \times 1.25^{\circ}$ and 30 vertical levels. Each member begins from an identical state in 1920 with a different random perturbation on the order of the round-off error of the atmospheric temperatures. Here, the monthly historical forcing simulations (1920-2005) are used for analyses. The variables used here include surface air temperature, geopotential height, and sea ice fraction. All of these variables presented in this study are based on the ensemble mean of the 40 members from CESM-LE.

\section{b. Method}

This study mainly adopted correlation and regression analysis to examine the relationships between the variations of lake ice phenology at LQH and the Kara Sea ice. The statistical significance was assessed using the Student's $t$ test. We also applied the Eliassen-Palmer (EP) flux to calculate wave activity divergence of 
planetary waves, which further indicates the eddy forcing of the zonal mean flow (Edmon et al. 1980). The meridional and horizontal components of EP flux $\mathbf{F}$ as well as its divergence $D_{F}$ are defined as follows:

$$
\begin{aligned}
F_{y} & =-\rho a \cos \varphi \overline{u^{\prime} v^{\prime}}, \\
F_{z} & =\rho a \cos \varphi \frac{R f}{H N^{2}} \overline{v^{\prime} T^{\prime}}, \quad \text { and } \\
D_{F} & =\frac{\nabla \cdot \mathbf{F}}{\rho a \cos \varphi},
\end{aligned}
$$

where $\rho$ is the air density, $a$ is the radius of Earth, $\varphi$ is the latitude, primes indicate the zonal deviation, and overbars denote the zonal average. Also, $R$ represents the gas constant, $f$ is the Coriolis parameter, $H$ is the constant scale height, $N^{2}=\left(R P^{\kappa} / H\right)(\partial \theta / \partial z)$ is the buoyancy frequency squared, where $\theta$ denotes the potential temperature and $P$ is the air pressure, and $\kappa$ is defined as $R$ normalized by the specific heat of air for constant pressure.

Furthermore, the horizontal wave activity flux (WAF) is also calculated to demonstrate its propagation based on the method proposed by Takaya and Nakamura (2001):

$$
\mathbf{W}=\frac{P}{2|\mathbf{U}|}\left\{\begin{array}{c}
\bar{u}\left(\psi_{x}^{\prime 2}-\psi^{\prime} \psi_{x x}^{\prime}\right)+\bar{v}\left(\psi_{x}^{\prime} \psi_{y}^{\prime}-\psi^{\prime} \psi_{x y}^{\prime}\right) \\
\bar{u}\left(\psi_{x}^{\prime} \psi_{y}^{\prime}-\psi^{\prime} \psi_{x y}^{\prime}\right)+\bar{v}\left(\psi_{y}^{\prime 2}-\psi^{\prime} \psi_{y y}^{\prime}\right) \\
\frac{f^{2}}{N^{2}}\left[\bar{u}\left(\psi_{x}^{\prime} \psi_{z}^{\prime}-\psi^{\prime} \psi_{x z}^{\prime}\right)+\bar{v}\left(\psi_{y}^{\prime} \psi_{z}^{\prime}-\psi^{\prime} \psi_{y z}^{\prime}\right)\right]
\end{array}\right\} .
$$

Here, $\psi$ denotes the streamfunction, $f$ is the Coriolis parameter, $\mathbf{U}$ is the horizontal wind velocity, and the overbars and primes denote the December mean and monthly disturbances regressed on a normalized Kara Sea ice cover index, respectively.

\section{Results}

\section{a. Change in characteristics of lake ice phenology over $L Q H$}

On average, ice formation in LQH generally starts on 15 December and complete ice break-up occurs on 11 April, resulting in 117 days of lake ice cover (figure not shown). Previous studies have revealed that the variations in lake ice phenology in the North Hemisphere are closely associated with the recent global warming trends, with a concrete manifestation of delayed freezing events, earlier thaw dates, and shortened ice duration days (e.g., Benson et al. 2012). Similar phenomena can also be seen in lake ice phenology changes over LQH. Figure 2 shows the time series of lake ice phenology over LQH during 1979-2016. The results reveal that there is a relatively weak trend in delaying the freeze-up date at LQH, implying the postponement of the beginning of the ice-cover period. In addition, the tendency in ice break-up date over LQH is presented to be shifted to an earlier date at decreasing rate of 0.37 days $\mathrm{yr}^{-1}$. Consequently, it is clear that the ice duration has a significant downward trend, which corresponds well with global warming trends. This indicates that lake ice phenology over the TP is very susceptible to climate change, a phenomenon evident in the observations of this case. Moreover, the variations of lake ice phenology are also characterized by a strong interannual variability, especially for the change in freeze-up date.

Some studies have indicated that the lake ice process is generally connected to the lake internal properties (e.g., surface area, mean depth, and altitude) and external meteorological conditions (e.g., Dong et al. 2018; Korhonen 2006). Some evidence has indicated that the lake ice phenology presents a close relationship with the regional surface air temperature (e.g., Latifovic and Pouliot 2007; Liu et al. 2018). In addition, some studies have also pointed out that the regional wind velocity and precipitation can also play a relatively important role in the variations of lake ice phenology for some lakes over the world (Sánchez-López et al. 2015; Wang et al. 2017). For example, Sánchez-López et al. (2015) have documented that lake ice phenology over northern Europe is primarily affected by the air temperature, while the precipitation strongly determines the change in lake ice cover over southern Europe. Hence, it is necessary to investigate whether these meteorological factors can exert great influences on the lake ice phenology over LQH. Figure 3 shows the scatterplots of the lake ice parameters with local near-surface air temperature, precipitation, and near-surface wind averaged around the LQH region, including the Gangcha, Gonghe, and Chaka sites. The results present a close relationship between the ice freeze-up date at $\mathrm{LQH}$ and the local near-surface air temperature, with the correlation coefficient being 0.34 , while a relatively weak correlation can be observed with the wind velocity $(-0.29)$. This implies that the regional surface air temperature is the dominant factor in determining the freeze-up date over LQH. Additionally, relatively higher correlations are also observed between the ice break-up date/ice duration days and the near-surface air temperature, implying that variations in temperature might mainly account for the changes in lake ice phenology over LQH. Thus, in the following we will put more emphasis on the 


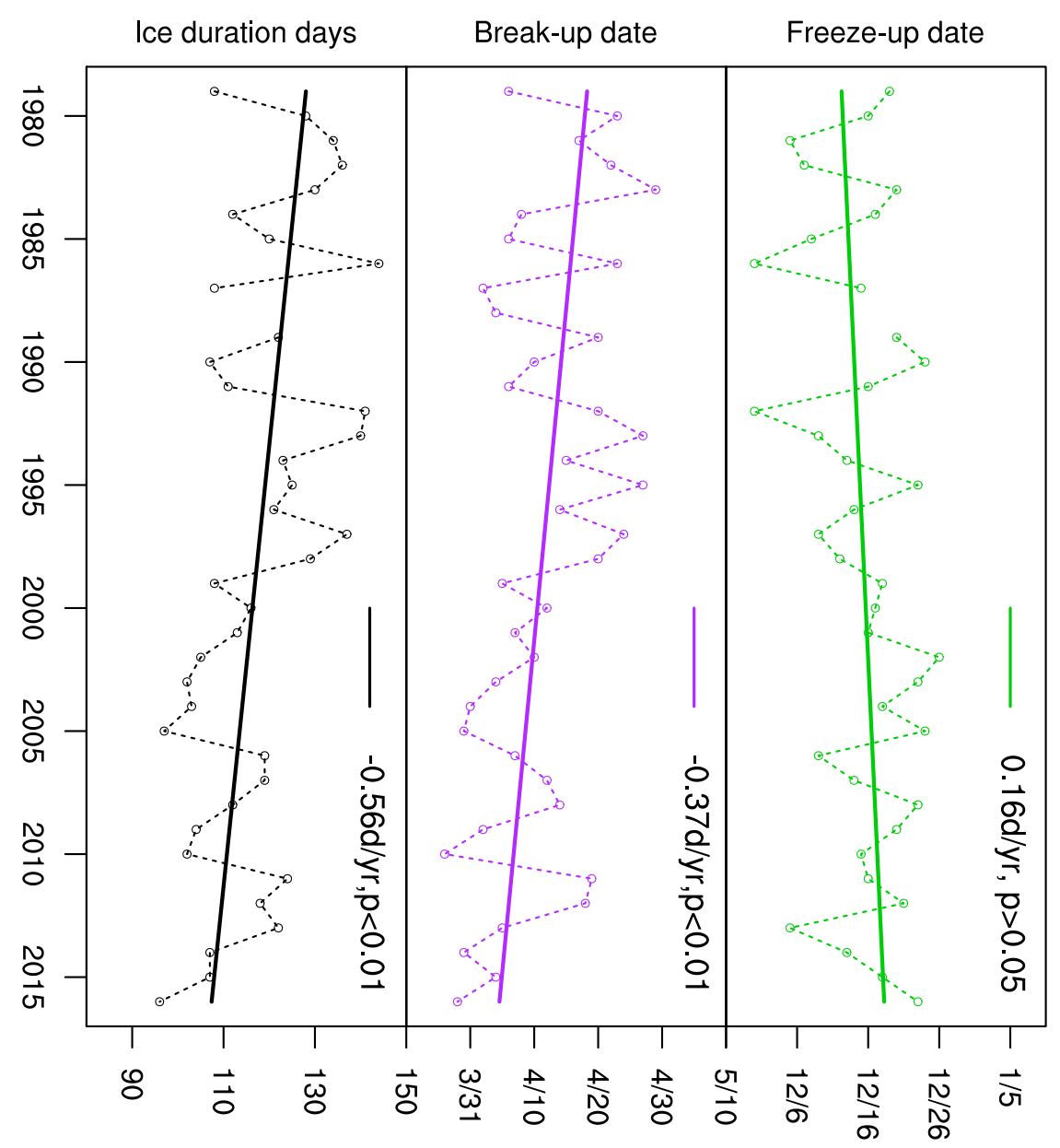

FIG. 2. Time series of lake ice phenology characteristics at LQH for the period of 19792016. The straight lines represent the linear trends that were calculated using the least squares method.

interannual variability of the freeze-up date and its association with the change in regional surface air temperature related to the Kara SIC variation.

\section{b. Atmospheric anomalies for ice freeze-up dates over $L Q H$}

To explore the local atmospheric circulation anomalies that are associated with the variations in the lake ice phenology over LQH, regression patterns of the atmospheric circulation anomalies versus the ice freeze-up are evaluated in Fig. 4. To facilitate comparisons in the following analysis, we multiply -1 by a normalized freeze-up index in this case. It is clear to see that the surface air temperature (SAT) pattern obtained from ERA-Interim reanalysis is characterized by a warm Arctic-cold Eurasia pattern, with the most significant low-temperature anomalies occurring in the BaikalMongolia regions and East Asia. Accordingly, LQH experiences an earlier freeze-up date, consistent with the statistical relationship between lake ice phenology and regional mean temperature over the $\mathrm{LQH}$ region as mentioned above. In addition to the negative temperature anomalies in the Eurasian continent, positive sea level pressure (SLP) anomalies are dominant in the middle to high latitudes of Eurasia, resulting in the intensification of the Siberian high. The intensified Siberian high can lead to cold advection and the frequent occurrence of cold events over East Asia (e.g., Takaya and Nakamura 2005). Moreover, the upper-level atmospheric circulation anomalies show a dipole pattern, with positive geopotential height anomalies in high latitudes and negative geopotential height anomalies over East Asia at the 500-hPa level. Based on the theory of geostrophic wind, this dipole structure of geopotential height fields can result in weakened westerlies in the middle latitudes and benefit cold air intrusion from the high latitudes, consistent with zonal wind anomalies in Fig. 4d. Briefly, such atmospheric circulation anomalies 


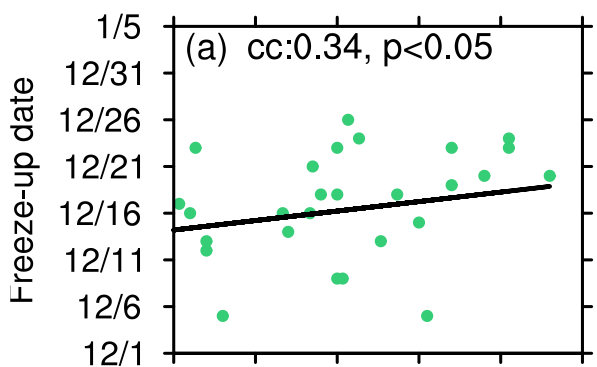

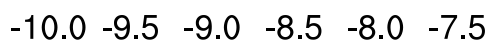
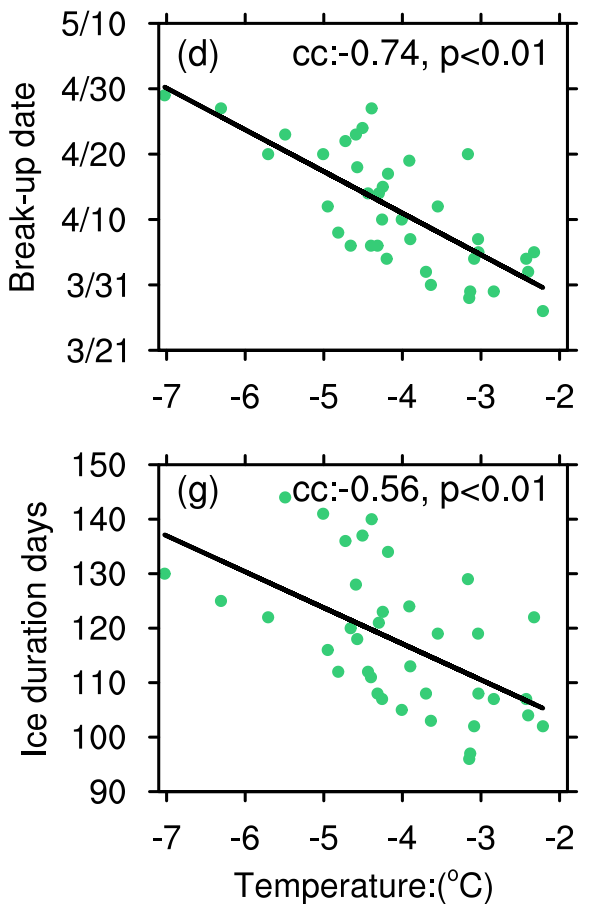
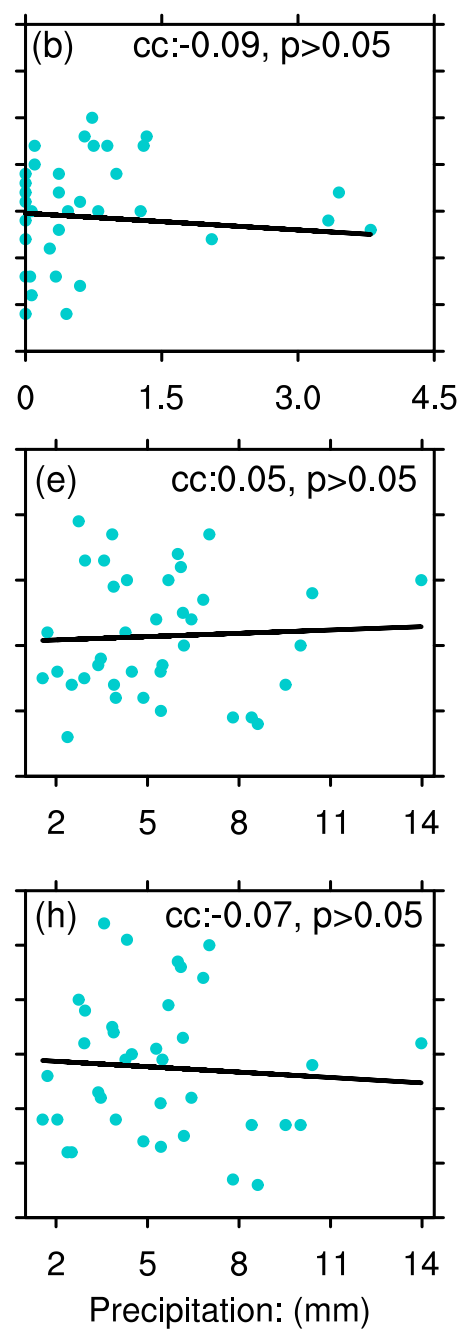
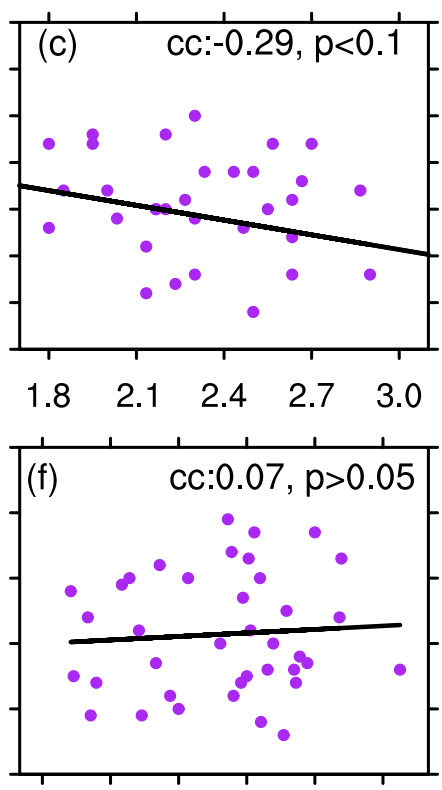

$\begin{array}{llllll}2.0 & 2.3 & 2.6 & 2.9 & 3.2 & 3.5\end{array}$

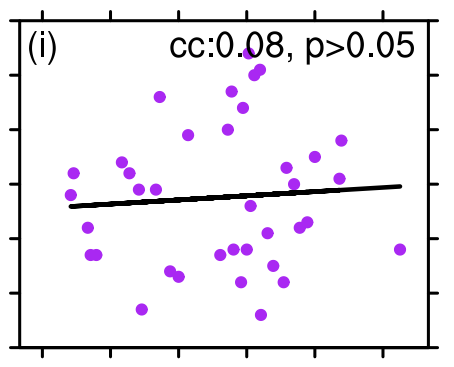

$\begin{array}{llllll}2.0 & 2.3 & 2.6 & 2.9 & 3.2 & 3.5\end{array}$ Surface wind velocity: $(\mathrm{m} / \mathrm{s})$

FIG. 3. The scatter maps of (a)-(c) freeze-up date, (d)-(f) break-up date, and (g)-(i) ice duration days against the meteorological variables during 1979-2016: (left) the averaged surface air temperature, (center) the cumulative precipitation, and (right) the averaged surface wind velocity. The local meteorological variables are obtained from in situ observation, including the Gangcha, Gonghe, and Chaka sites. The freeze-up date corresponds to the monthly average meteorological variables in December, and the break-up and ice duration correspond to the seasonal average meteorological variables for January-April.

can advance the freeze-up date over $\mathrm{LQH}$ by providing a favorable environment for cold air intrusion and lowering the temperature over the $\mathrm{LQH}$ region.

Clearly, the anomalous atmospheric circulation in the middle and high latitudes plays an important role in the variations of lake ice phenology over LQH. Some early studies have documented that the Arctic sea ice decline in recent decades has exerted remote effects on the large-scale pressure field and geostrophic wind anomalies over the midlatitudes (e.g., Vihma 2014). Liu et al. (2012) have also indicated that the diminishing autumn Arctic sea ice could induce positive SLP anomalies over high latitudes and negative SLP anomalies over the midlatitudes in winter, accompanied by significant surface warming in the Arctic Ocean and cooling over
Europe, Siberia, and East Asia. The research question we thus aim to address in this study is whether the variation of Arctic sea ice can exert impacts on the lake ice phenology changes over LQH.

\section{c. Impacts of Kara Sea ice on the freeze-up dates over $L Q H$}

The atmospheric circulation anomalies related to the variations in lake ice phenology over LQH have been discussed in the previous sections. Our further analysis shows a high correlation (0.41) between the variations of the November Kara Sea ice and the freeze-up date of $\mathrm{LQH}$ in the past decades, which is significant at the $95 \%$ confidence level. In this section, the issue of whether these atmospheric circulation anomalies related to the 
(a) SAT\&FU

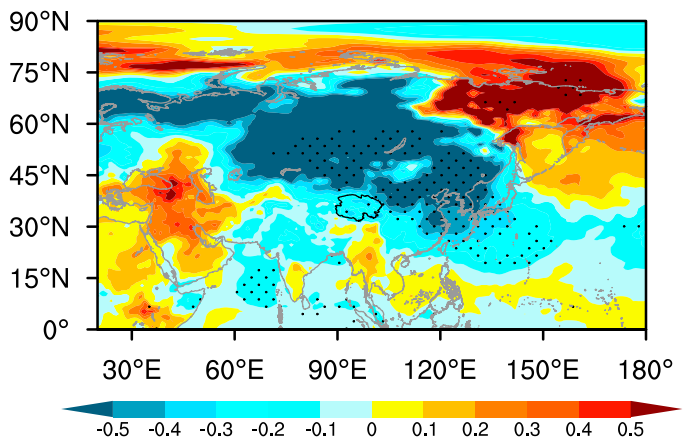

(c) Z500\&FU

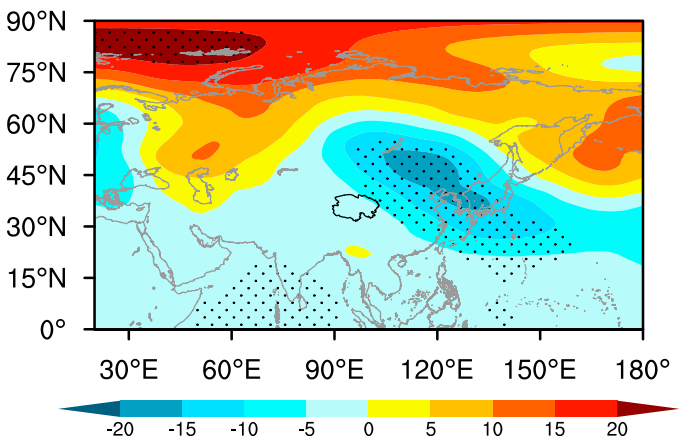

(b) SLP\&FU

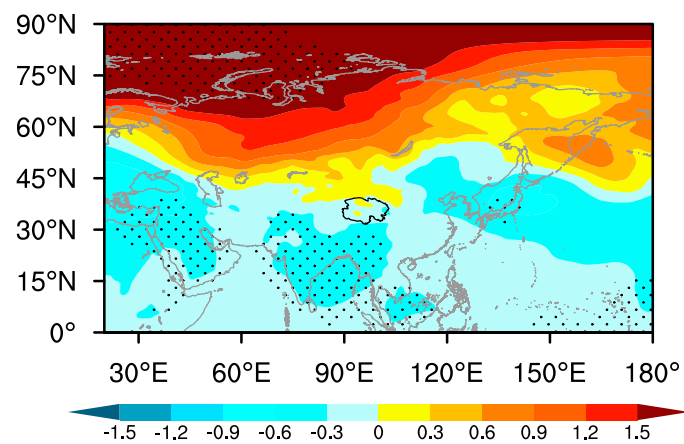

(d) U200\&FU

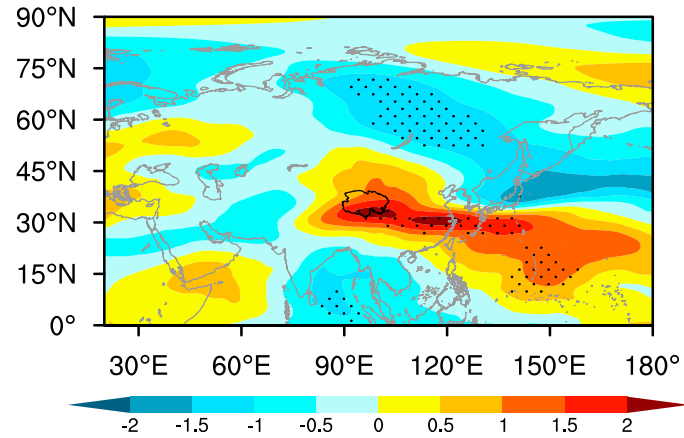

FIG. 4. Regression maps of monthly (a) SAT, (b) SLP, (c) 500-hPa geopotential height, and (d) 200-hPa zonal wind anomalies against the freeze-up index (multiplied by -1) at LQH in December 1979-2015. The linear trends of the SAT, SLP, 500-hPa geopotential height, and 200-hPa zonal wind have been removed before the regression analysis. The black dots indicate significant regression at the $90 \%$ confidence level using the Student's $t$ test.

variation in the freeze-up date of $\mathrm{LQH}$ resulted from the declining Arctic sea ice will be discussed.

Figure 5 shows the correlation map between the November Arctic sea ice concentrations and the lake ice freeze-up dates in the following Decembers of 19792015 at LQH. Clearly, a significantly high-correction center can be seen over the Kara Sea $\left(74^{\circ}-80^{\circ} \mathrm{N}, 60^{\circ}-\right.$ $90^{\circ} \mathrm{E}$ ), implying possible impacts from the variations of Kara Sea ice on the lake ice freeze-up date changes in LQH. In addition, Fig. $5 \mathrm{~b}$ presents the detrended time series of the November Kara Sea ice and the lake freezeup dates from 1979 to 2016 . Their correlation coefficient

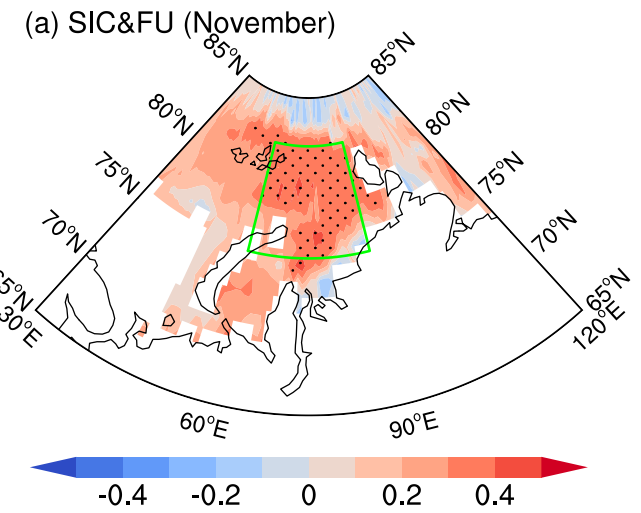

(b)

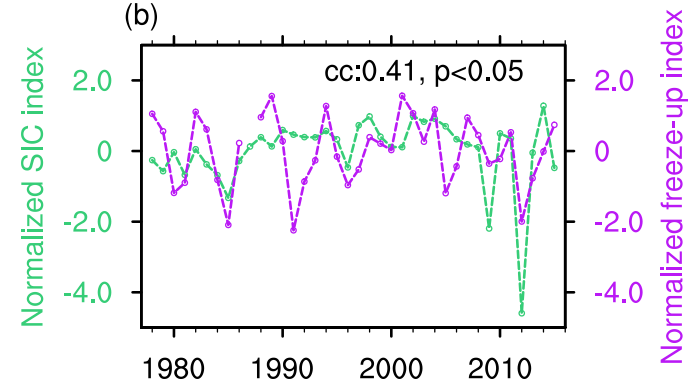

FIG. 5. (a) Correlation map between SIC in November and the freeze-up index at LQH during 1979-2015 (the green box represents the Kara Sea) and (b) the time series plot of variations in the normalized Kara SIC index and the normalized freeze-up index during 1978-2015. The linear trends of the freeze-up date and SIC were removed before the correlation analysis. The black dots indicate significant regression at the $90 \%$ confidence level with the Student's $t$ test. 
(a) SAT\&SIC

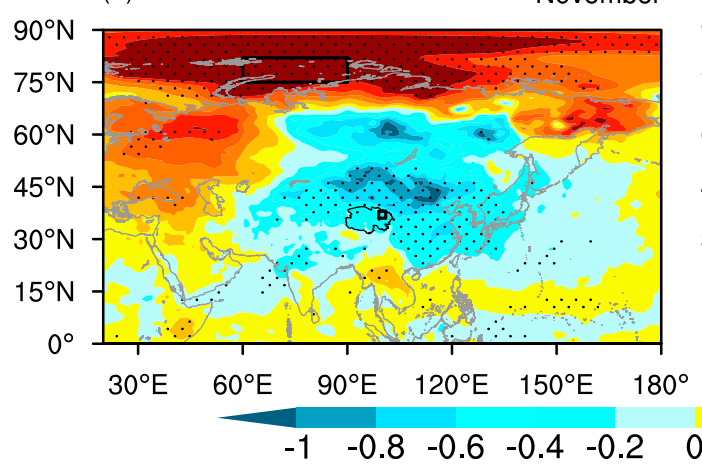

(b) SAT\&SIC

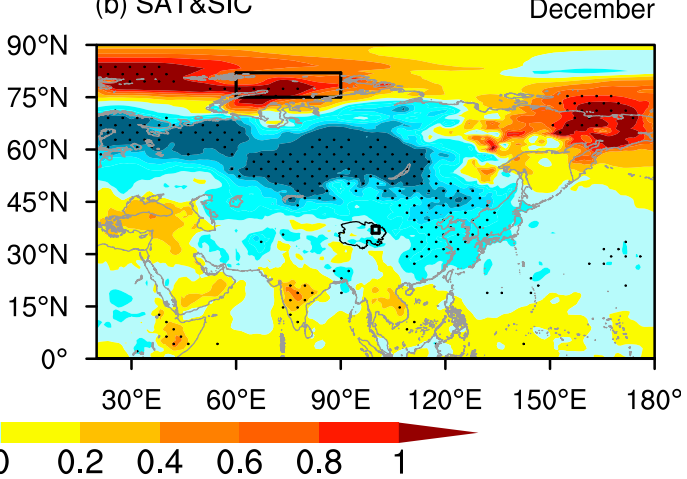

(c) SLP\&SIC

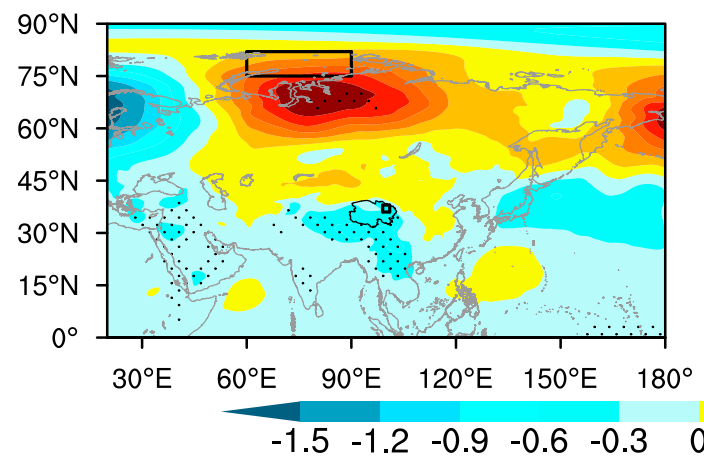

(d) SLP\&SIC

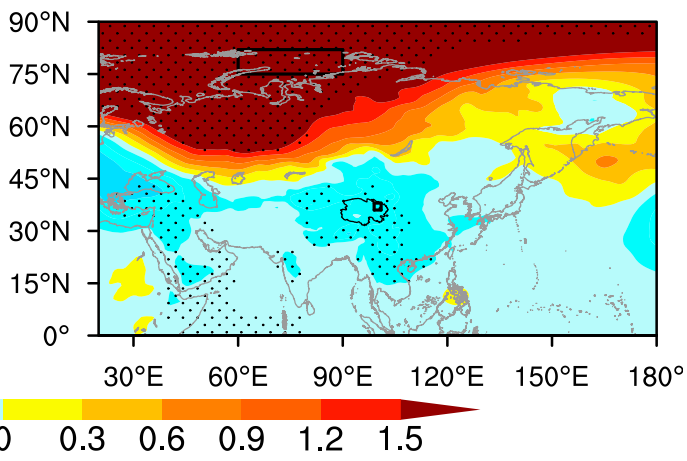

FIG. 6. Regression maps of (a),(b) SAT and (c),(d) SLP anomalies against the Kara SIC index (multiplied by -1) at LQH during 1979-2015 for (left) November and (right) December. The linear trends of the SAT and SLP were removed before the regression analysis. The black dots indicate significant regression at the $90 \%$ confidence level with the Student's $t$ test. The bigger black rectangle represents the Kara Sea region studied in this paper, and the smaller black rectangle indicates the LQH.

can be up to 0.41 for the entire period after their linear trends are removed, which is significant at the $95 \%$ confidence level. Additionally, strong interannual variability can also be observed for both SIC and lake ice freeze-up date.

To explore the possible role of Kara Sea ice on the changes in lake ice phenology over LQH, the linkages between the large-scale atmospheric circulation anomalies and SIC are investigated in this study. Figure 6 shows regression maps of Kara Sea ice in November with regard to the simultaneously anomalous SAT and SLP in 1979-2016 as well as with respect to the anomalous SAT and SLP in December. The regression patterns of atmospheric circulation anomalies resemble the results shown in Fig. 4. Clearly, the negative temperature anomalies over the Eurasian continents are associated with positive SLP anomalies over the Siberian regions. It is found that in November, the positive high SLP anomalies extend from the coast of the Kara Sea to the central Eurasian continent. In December, the positive SLP anomalies dominate all of the high latitudes and extend to the Arctic regions, indicating the continuity of Kara Sea ice impacts on climate anomalies. Moreover, the upper-level atmospheric circulation anomalies also present a dipole structure with positive geopotential height anomalies in high latitudes and negative geopotential height anomalies over East Asia, accompanied by weakened westerlies in the midlatitudes (Fig. 7). The negative anomaly at a high level over East Asia implies an eastward shift and deepening of the East Asian trough, leading to the strength of the East Asian winter monsoon, with more cold air intruding from high latitudes and then resulting in more extreme cold events across East Asian regions (Zhang et al. 1997). Correspondingly, the increasing northerly winds from low to high levels, especially in the December, could transport the cold and dry air to the East Asian regions from the Arctic and Siberian regions, resulting in low-temperature anomalies over the LQH regions (Fig. 8).

As discussed above, the variations in the lake ice freeze-up dates at $\mathrm{LQH}$ are closely associated with the 
(a) Z500\&SIC

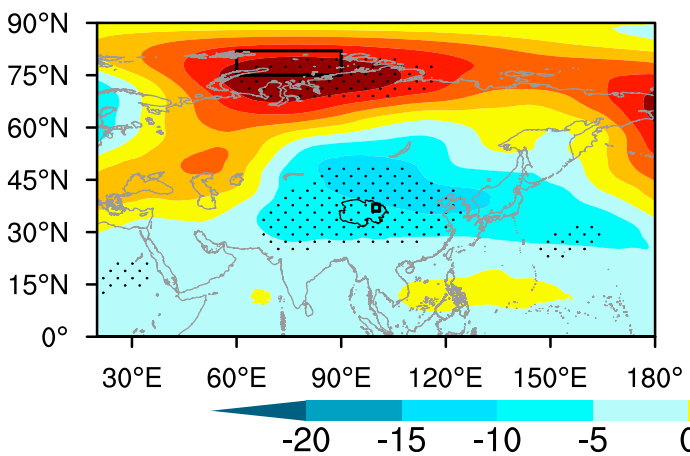

(b) Z500\&SIC

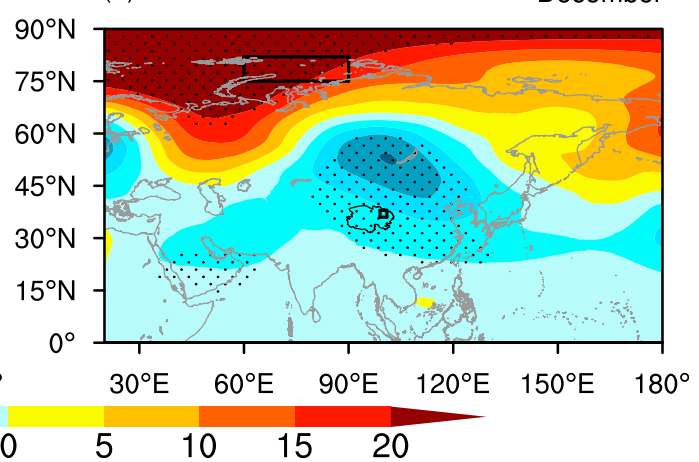

(c) U200\&SIC

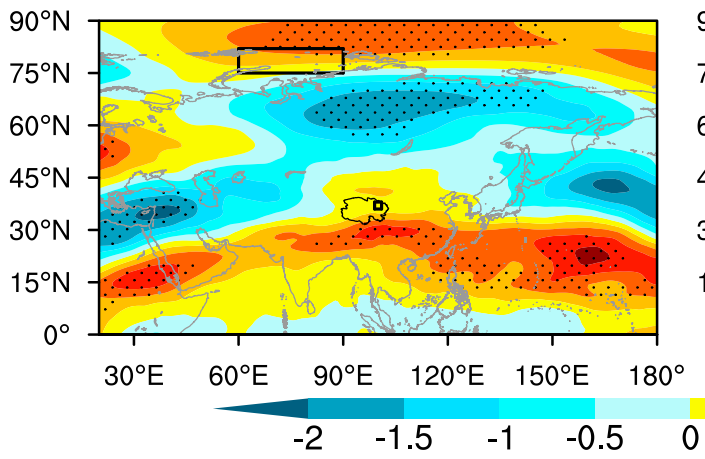

(d) U200\&SIC

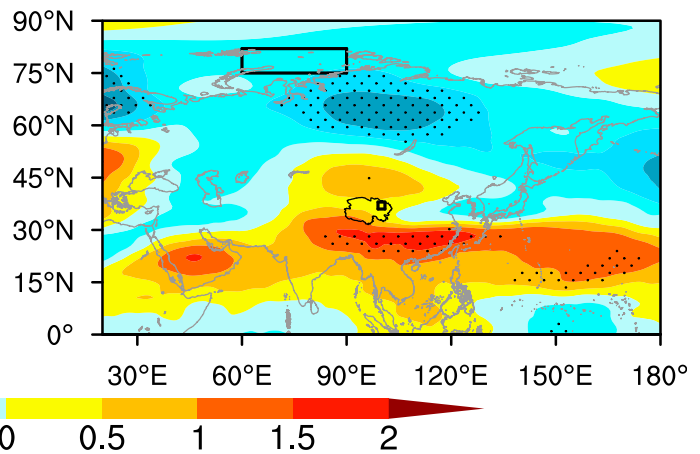

FIG. 7. As in Fig. 6, but for the regression maps of 500-hPa geopotential height and 200-hPa zonal wind anomalies in November and December against the Kara SIC index (multiplied by -1) in November.

simultaneous local surface air temperature and wind speed. The Kara Sea ice plays an important role in the variations in lake ice phenology at LQH through reinforcing cold air intrusion from high latitudes and lowering the Eurasian continent temperature. Thus, the low-temperature anomalies over the LQH regions would advance the lake ice freeze-up dates. However, how the signal from the variation in November Kara Sea ice persisted and then exerted impacts on the lake ice freeze-up in December LQH is still unclear.

Figure 9 displays the EP flux anomalies and the associated divergence in December obtained by regressions upon the normalized Kara SIC index (multiplied by -1$)$. Clearly, the strongest changes including anomalous upward propagation of stationary planetary waves are visible at high latitudes in the upper troposphere and low stratosphere. The most pronounced upward planetary wave EP flux occurs between 500 and $50 \mathrm{hPa}$ in the latitudinal belt north of $70^{\circ} \mathrm{N}$, accompanied by significant EP flux convergence at approximately $65^{\circ}-80^{\circ} \mathrm{N}$ and divergence at approximately $40^{\circ}-50^{\circ} \mathrm{N}$. According to the theory of the wave-mean flow interaction (Eliassen and Palm 1961), the convergence of EP flux would result in the deceleration of zonal winds, while the divergence of
EP flux results in the acceleration of zonal winds. Correspondingly, the easterly wind anomalies occur over the middle and high latitudes of the Northern Hemisphere and westerly wind anomalies appear in the south of the midlatitudes. As indicated by Jaiser et al. (2012), the enhanced Arctic EP fluxes are identified as a result of a stronger diabatic heating source during the low sea ice years. Furthermore, it is found that the anomalous upward propagation of stationary planetary waves is observed simultaneously below $500 \mathrm{hPa}$ in the latitudinal belt north of $70^{\circ} \mathrm{N}$ (figure not shown), which indicates the continuity of the upward propagation of the EP flux.

To clarify the regulation from the variation of Kara Sea ice, we displayed the regression maps of quasigeostrophic streamfunction at $300 \mathrm{hPa}$ and horizontal wave activity flux with regard to the normalized SIC index over the Kara Sea as illustrated in Fig. 10. Obviously, an evident high-latitude Eurasian wave train prevails over the regions from northern Europe to the East Asia, with a positive center located over Kara Sea and negative centers over northern Europe and the Mongolia region, respectively. In addition, it is clear that there are two wave activity propagation pathways that divide from western Europe. The northern branch wave train 
(a) Surface wind \&SIC

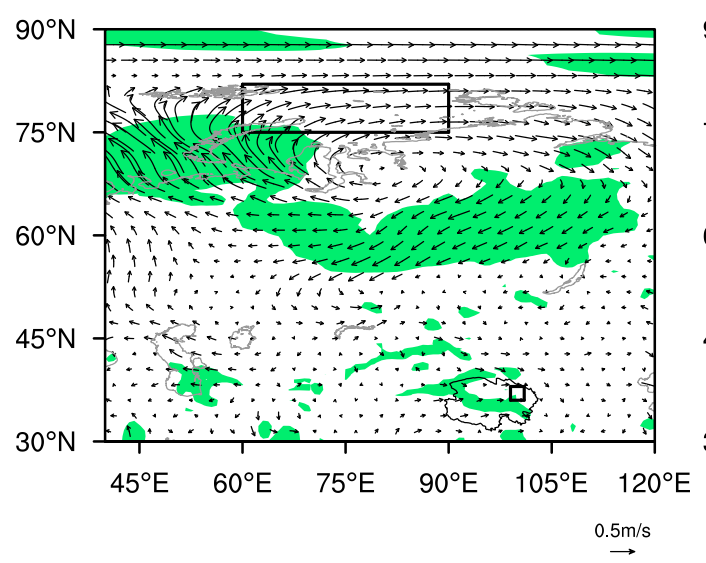

(c) V200\&SIC

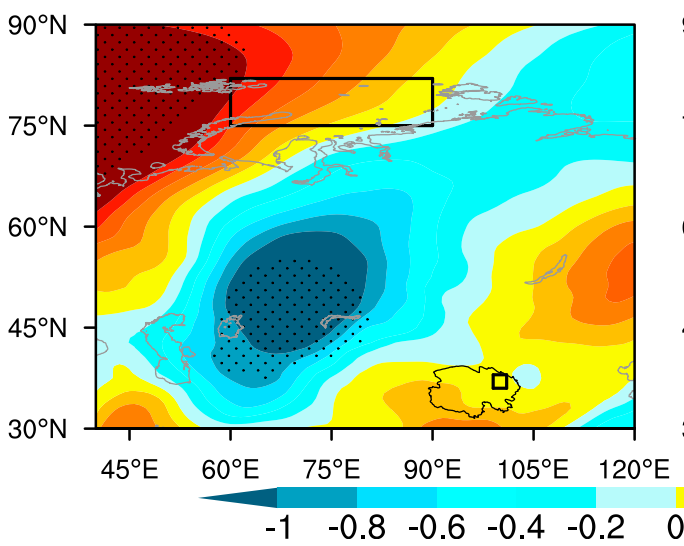

(b) Surface wind\&SIC

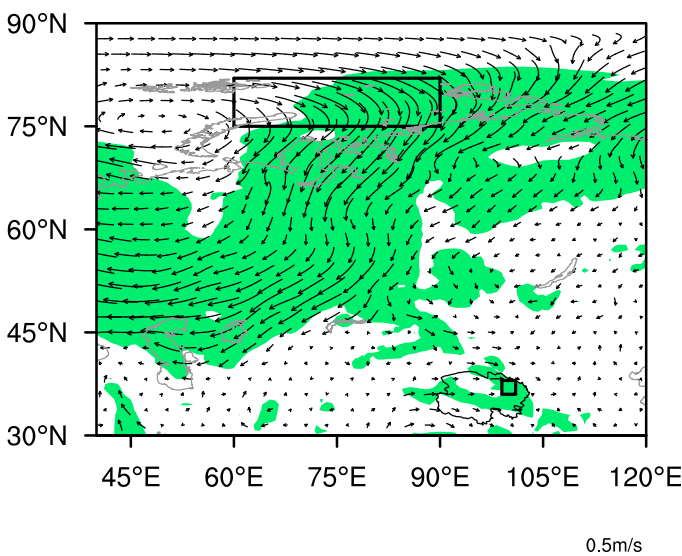

(d) V200\&SIC

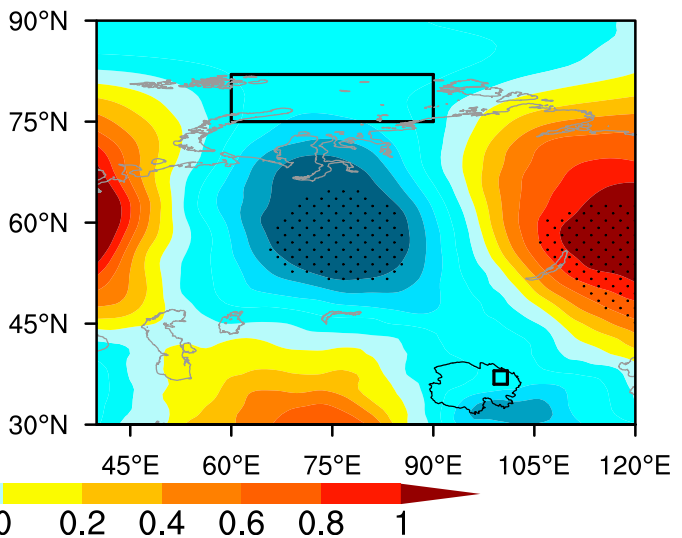

FIG. 8. As in Fig. 6, but for the regression maps of near-surface $(10 \mathrm{~m})$ wind vectors and 200 -hPa meridional wind anomalies in November and December against the Kara SIC index (multiplied by -1 ) in November.

propagates from northern Europe, then eastward to Kara Sea along the polar region, and finally southeastward to East Asia. But it is worth noting that this wave propagation becomes weak and discontinuous as it spreads to the eastern European plain, and instead it is reinforced around the Kara Sea. Hence, this strengthened Eurasian wave train over high-latitude regions may be attributed to the thermal forcing related to anomalous Kara SIC variation. In the following December, the arcuate wave train along the high-latitude regions still persists and becomes more significant, and then deepens the East Asian trough. Early studies have discussed the linear interference between forced and climatological wave propagation in affecting the atmospheric circulation (e.g., Orsolini et al. 2015; Smith et al. 2011; Zhang et al. 2017). In general, when the forced and climatological wave trains are in the same phase, the atmospheric circulation will be stronger. To determine the important role of the forced wave propagation related to Kara SIC superimposing on the climatological wave propagation in atmospheric circulation, we also conducted similar analysis. As indicated by Fig. 11a, the forced and climatological wave trains are in phase over the Barents-Kara Sea and north of Baikal but out of phase over eastern Kara Sea and eastern European plain. The constructive (destructive) linear interference over western Kara Sea (eastern European plain) indicates the enhanced (weakened) wave activity propagation, which corresponds well to the previous analysis. Concerning waves $1-4$, the most significant phenomenon is that the forced and climatological wave trains are out of phase over Eurasia with the spatial correlation coefficients being -0.55 and -0.57 for waves 3 and 4 , respectively, which implies that the forced wave trains would weaken the climatological wave trains and prompt an influence on the climate over northern TP. Substantially, in terms of the total wave, it can be found that the constructive (destructive) linear interference between the forced and climatological wave trains over the region south of the Kara Sea and Lake Baikal (the East European plain) can persist in the following December. And the change in atmospheric circulation over 


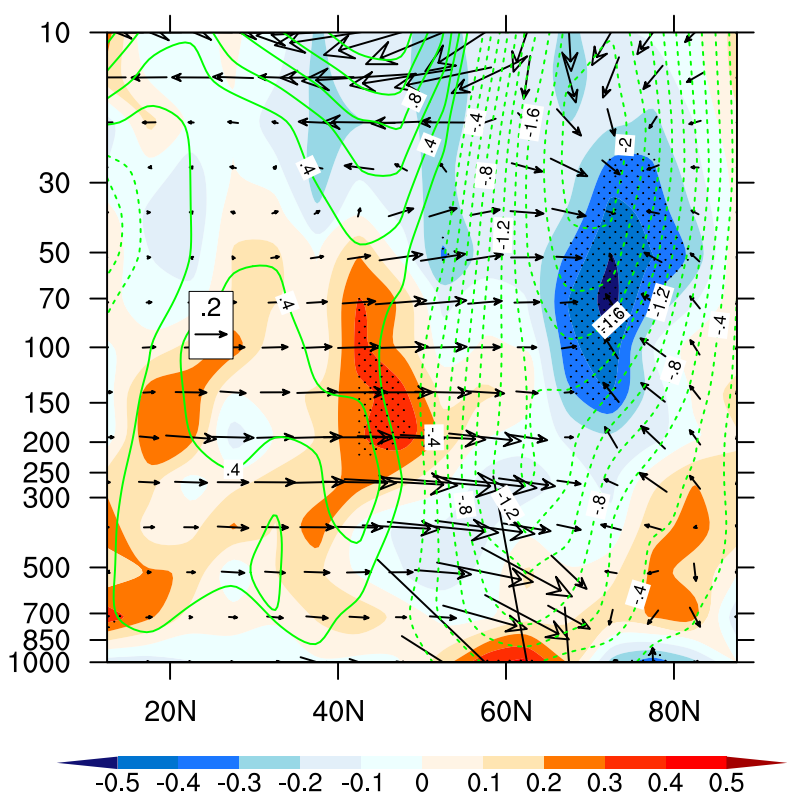

FIG. 9. Regression maps of zonal mean wind (the green contours) and the divergence of EP flux (shading) in December against the Kara SIC index (multiplied by -1 ) in November. The vectors represent the EP flux. In addition, the linear trends have been removed before the regression analysis. The black dots indicate significant regression at the $90 \%$ confidence level with the Student's $t$ test.

the northern TP can be attributed to the weakened (strengthened) wave propagation for wave 1 , wave 3 , and wave 4 (wave 2).

\section{d. Causality validation by large ensemble simulations of CESM}

The large ensemble simulations from the CESM model (CESM-LE) are used to further validate whether these relationships can be reproduced by the model. The CESM-LE ensemble-mean variables from 40 historical experiments are employed to investigate the atmospheric circulation anomalies associated with lake ice in the LQH that respond to the Kara Sea ice changes. For each variable, the ensemble means are first calculated and then applied to the composite analysis to highlight the differences in varying climatic states.

To better understand the possible remote impact of Kara SIC variation in November on the regional atmospheric circulation, we calculated the SIC index in the Kara Sea region from the CESM-LE ensemble mean dataset. The extreme SIC years are defined when the detrended November Kara SIC index is larger than 1.2 standard deviations. There are three years with high sea ice and three years with low sea ice selected from the period 1979-2005 according to this definition. Here the time period selected from the historical forcing (a) WAF\&SIC

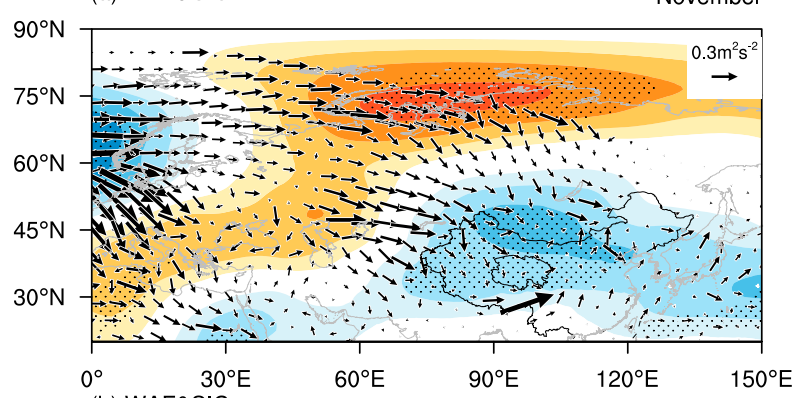

(b) WAF\&SIC

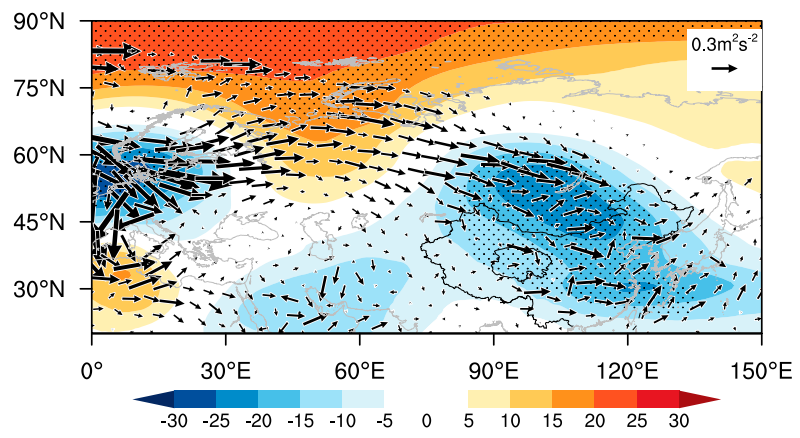

FIG. 10. Regression maps of geostrophic streamfunction anomalies $\left(10^{5} \mathrm{~m}^{2} \mathrm{~s}^{-1}\right)$ in (a) November and (b) December against the Kara SIC index (multiplied by -1) during 1979-2015 in November. The vectors represent the anomalous wave activity flux $\left(\mathrm{m}^{2} \mathrm{~s}^{-2}\right)$. The linear trends were removed before the regression analysis. The black dots indicate significant regression at the $90 \%$ confidence level with the Student's $t$ test.

experiments is chosen to correspond with the time period chosen from the observation.

In terms of the atmospheric circulation anomalies with regard to Kara Sea ice, the composite differences of SAT and 500-hPa geopotential height between the high years and the low years of Kara Sea ice are presented in Fig. 12. The SAT pattern obtained from the CESM-LE ensemble mean is characterized by the warm Arcticcold continents pattern, similar to the SAT change pattern obtained from the ERA reanalysis data. The difference in the SAT pattern between the simulations and observations is that the simulated temperature anomaly in northern Europe is overestimated compared to the observation. Early studies (e.g., Mori et al. 2014) have argued that the SAT pattern identified as warm Arctic and cold Eurasia is a direct atmospheric response to the sea ice variation over the Barents and Kara Seas. In addition to the warming over the Arctic, the associated atmospheric circulation anomalies at $500-\mathrm{hPa}$ geopotential height are reproduced by the ensemble-mean response to altered SIC, with positive geopotential height anomalies in the high latitudes and negative geopotential height anomalies in the midlatitudes. In general, the atmospheric circulation anomalies that are 
(a) Total Wave (Nov) $\quad \mathrm{R}=0.01$

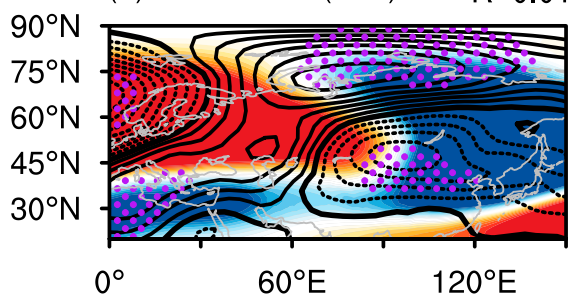

(c) Wave1 (Nov)

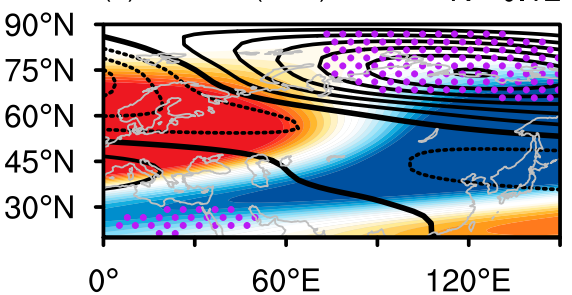

(e) Wave2 (Nov)

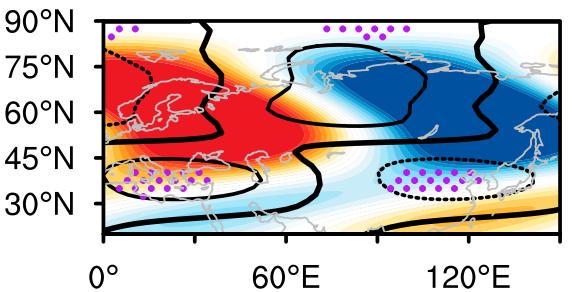

(g) Wave3 (Nov)

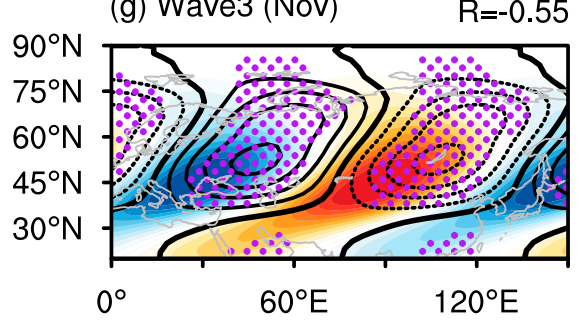

(i) Wave4 (Nov)

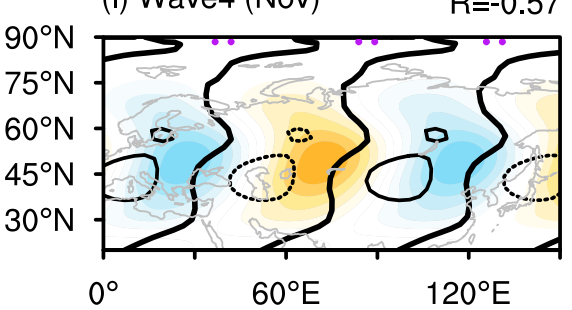

$\begin{array}{lllll}-50 & -40 & -30 & -20 & -10\end{array}$ (b) Total Wave (Dec)

$R=-0.06$

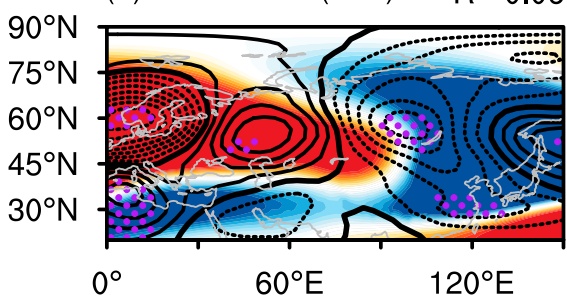

(d) Wave1 (Dec)

$\mathrm{R}=-0.53$

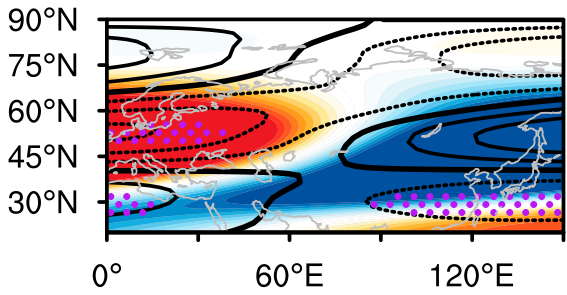

(f) Wave2 (Dec)

$\mathrm{R}=0.34$

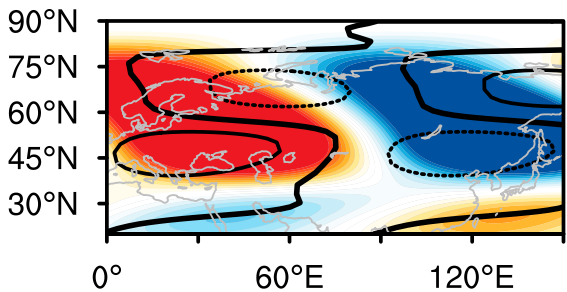

(h) Wave3 (Dec)

$\mathrm{R}=-0.57$

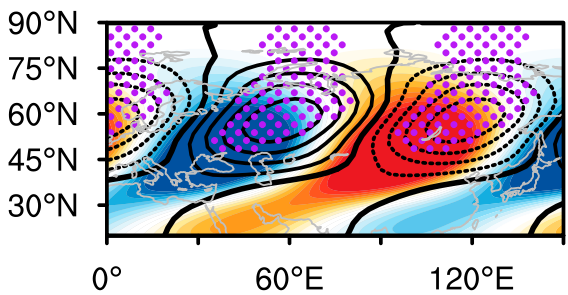

(j) Wave4 (Dec)

$\mathrm{R}=-0.53$

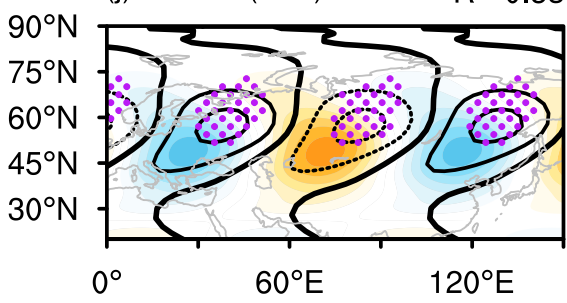

\section{$\begin{array}{llllll}0 & 10 & 20 & 30 & 40 & 50\end{array}$}

FIG. 11. Kara SIC forced (contours) and climatological (shading) stationary waves represented by (left) November and (right) December 300-hPa geopotential heights for (a),(b) the total wave and (c)-(j) zonal wavenumbers 1-4. The stationary waves are retrieved by removing the zonal average geopotential heights. The spatial coefficients between the forced and climatological waves are denoted by $R$. Contour intervals are $4 \mathrm{gpm}$ for the forced waves, including the total wave and zonal wavenumbers $1-4$. The purple dots indicate significant regression at the $90 \%$ confidence level with the Student's $t$ test. 
(a) SAT

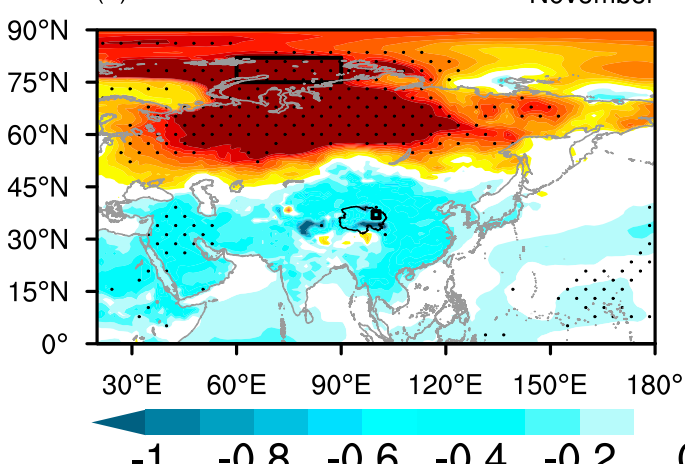

(b) SAT

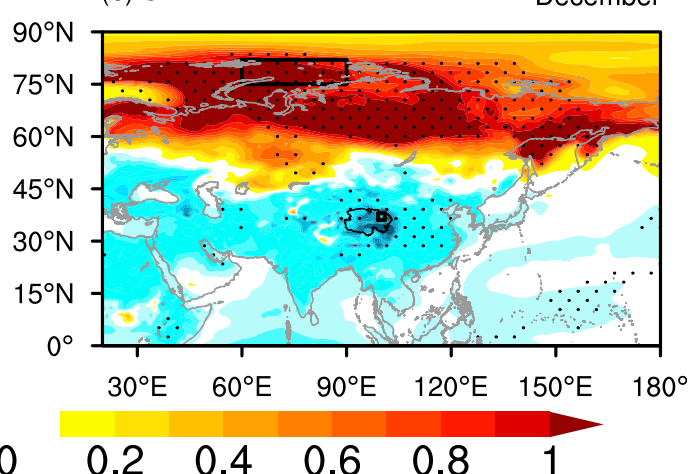

(d) Z500

December

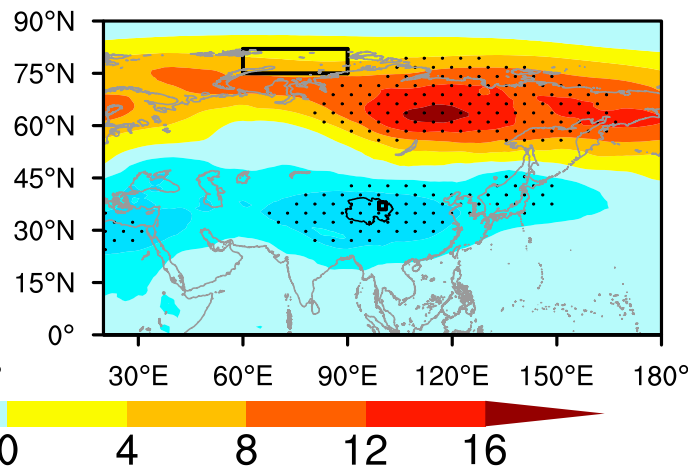

FIG. 12. The composite maps of (a),(b) SAT, and (c),(d) 500-hPa geopotential height anomalies in November and December between the three lowest and the three highest Kara Sea SIC years during 1979-2005 based on the 40 CESM-LE experiments. The extreme SIC years are defined when the detrended November Kara SIC index is more than 1.2 standard deviations. The black dots indicate significant regression at the $90 \%$ confidence level with the Student's $t$ test.

associated with variations of lake ice freeze-up date at LQH can be reproduced by the CESM-LE simulations responding to the variation of Kara Sea ice. The decreased Kara Sea ice in November thus might be one of the contributing drivers for the variation in ice freeze-up date at $\mathrm{LQH}$.

\section{Discussion and conclusions}

Previous studies have indicated that it is of great limnological and ecological significance to study the climatic controls on the great lakes around the world (Todd and Mackay 2003). LQH is the largest inland and slightly saline lake in the TP, which exerts a great influence on the surrounding semiarid ecosystem, hydrometeorology, and regional climate (Wang et al. 2014; Zhao et al. 2017; Zhu et al. 2018). Lake ice phenology has been a good proxy for climate monitoring and is important for limnology and ecology, and has potential implications for understanding the sedimentary record (Todd and Mackay 2003; Wang and Sun 2009). In this study, the changing characteristics of lake ice phenology are first explored over LQH from 1979 to 2016 using the datasets retrieved from satellite profiles. The results indicate that the freezing process generally starts in December and ice completely melts in April, with a delayed freeze-up process and an earlier break-up time in recent decades. Further analysis shows that the variations of ice freeze-up dates are closely linked to the surface air temperature and wind speed, while the break-up date and ice duration merely present a high correlation with the surface air temperature.

Our study further reveals that the reduction of the Kara Sea ice can advance the lake ice freezing process at LQH. During the low Kara Sea ice years, the strong diabatic heating source can enhance the upward planetary wave EP flux in the midtroposphere and low stratosphere, accompanied by significant EP flux divergence anomalies in the high latitudes and convergence anomalies in the midlatitudes, resulting in easterly anomalies over the middle and high latitudes and westerly anomalies in the subtropical regions. Therefore, the 
weakened westerly winds in the middle and high latitudes are favorable to strengthen the meridional winds, which might be beneficial for the intrusion of cold air from high latitudes. Furthermore, the enhanced Rossby wave propagation related to the Kara SIC variation spreading along the high latitude regions can deepen the East Asian trough. Also, the intensified deep trough favors the intrusion of cold air from high latitudes to the $\mathrm{LQH}$ region, leading to a decrease in the surface air temperature and then advancing the lake ice freeze-up date at LQH. In addition, the large ensemble simulations with 40 members from the CESM-LE model can also reproduce the atmospheric circulation anomalies associated with Kara Sea ice variation, which largely resembles the atmospheric circulation patterns linked to variations in lake ice freeze-up dates at $\mathrm{LQH}$.

Compared with earlier studies, some new insights can be derived from this study. First, the linkage between the Arctic and the Tibetan Plateau is established through investigating the impacts of Kara Sea ice variation on the variations of lake ice freeze-up dates in the TP. Second, the impact of the Kara Sea ice on the lake ice phenology of LQH has been explored in this study, unlike earlier studies that are only limited to the statistical relationship analysis. However, it is worth noting that the Kara Sea ice variation is not the only factor impacting the variations of lake ice phenology at LQH. A recent study has indicated that the winter NAO can also exert a great influence on the lake ice phenology over the southern TP via stimulating the Rossby wave train for the adjustment of atmospheric circulation (Liu et al. 2018). Shaman and Tziperman (2005) have also highlighted the role of stationary barotropic Rossby waves in ENSO affecting the Tibetan Plateau snow depth in the winter. Additionally, Zhao et al. (2017) have suggested that the precipitation and the changes in $\mathrm{LQH}$ volume were found to be related to the summer Eurasia wave train modulated by the North Pacific and Pacific decadal oscillation modes during the cold season. It is worth noting that the increase in the surface humidity during the winter and spring seasons can induce a relatively large increase in downward longwave radiation, resulting in warming over the Tibetan Plateau (Rangwala et al. 2009). Third, we reveal that the variation of the Kara Sea ice cover can advance the lake ice freezing process at $\mathrm{LQH}$, despite a slightly increasing trend seen in the observed ice freeze-up dates in recent decades that mainly result from the impact of global warming. More discussion of this aspect will be urgently needed in the future.

Although there is a debate about the impact of Arctic sea ice variation on midlatitude weather (Barnes and
Screen 2015), some efforts have been made to verify whether climate model simulations can reproduce the associated atmospheric circulation patterns (e.g., Seviour 2017). This study shows a clear explanation on how the Kara Sea ice exerts a great impact on the variations in freeze-up date over LQH. Certainly, more studies are still needed to explore the responsibility of the lake ice phenology change over the TP for a better understanding of variations in lake ice and to improve the prediction skills of lake ice phenology in the future.

Acknowledgments. This research was jointly supported by the Strategic Priority Research Program of the Chinese Academy of Sciences (Grant XDA19070201), the National Key Research and Development Program of China (Grant 2016YFA0600701), the open program of Joint Laboratory of Climate and Environment Change, Chengdu University of Information Technology (Grant JLCEC201801), and the CAS-PKU Joint Research Program.

\section{REFERENCES}

Barnes, E. A., and J. A. Screen, 2015: The impact of Arctic warming on the midlatitude jet-stream: Can it? Has it? Will it? Wiley Interdiscip. Rev.: Climate Change, 6, 277-286, https:// doi.org/10.1002/wcc.337.

Benson, B. J., and Coauthors, 2012: Extreme events, trends, and variability in Northern Hemisphere lake-ice phenology (18552005). Climatic Change, 112, 299-323, https://doi.org/10.1007/ s10584-011-0212-8.

Cai, Y., C.-Q. Ke, and Z. Duan, 2017: Monitoring ice variations in Qinghai Lake from 1979 to 2016 using passive microwave remote sensing data. Sci. Total Environ., 607-608, 120-131, https://doi.org/10.1016/j.scitotenv.2017.07.027.

Chen, G., and R. Huang, 2012: Excitation mechanisms of the teleconnection patterns affecting the July precipitation in northwest China. J. Climate, 25, 7834-7851, https://doi.org/ 10.1175/JCLI-D-11-00684.1.

Dee, D., and Coauthors, 2011: The ERA-Interim reanalysis: Configuration and performance of the data assimilation system. Quart. J. Roy. Meteor. Soc., 137, 553-597, https://doi.org/ 10.1002/qj.828.

Dong, H., Y. Song, and M. Zhang, 2018: Hydrological trend of Qinghai Lake over the last 60 years: Driven by climate variations or human activities? J. Water Climate Change, jwc2018033, https://doi.org/10.2166/wcc.2018.033.

Edmon, H. J., B. J. Hoskins, and M. E. Mcintyre, 1980: EliassenPalm cross sections for the troposphere. J. Atmos. Sci., 37, 2600-2616, https://doi.org/10.1175/1520-0469(1980)037<2600: EPCSFT $>2.0 . \mathrm{CO} ; 2$.

Eliassen, A., and E. Palm, 1961: On the transfer of energy in stationary mountain waves. Geofys. Publ., 22, 1-23.

Guo, D., J. Sun, and E. Yu, 2018: Evaluation of CORDEX regional climate models in simulating temperature and precipitation on the Tibetan Plateau. Atmos. Ocean. Sci. Lett., 11, 219-227, https://doi.org/10.1080/16742834.2018.1451725.

He, S., Y. Gao, T. Furevik, H. Wang, and F. Li, 2018: Teleconnection between sea ice in the Barents Sea in June and the Silk 
Road, Pacific-Japan and East Asian rainfall patterns in August. Adv. Atmos. Sci., 35, 52-64, https://doi.org/10.1007/ s00376-017-7029-y.

Jaiser, R., K. Dethloff, D. Handorf, A. Rinke, and J. Cohen, 2012: Impact of sea ice cover changes on the Northern Hemisphere atmospheric winter circulation. Tellus, 64A, 11595, https:// doi.org/10.3402/tellusa.v64i0.11595.

Kalnay, E., and Coauthors, 1996: The NCEP/NCAR 40-Year Reanalysis Project. Bull. Amer. Meteor. Soc., 77, 437-471, https:// doi.org/10.1175/1520-0477(1996)077<0437:TNYRP>2.0.CO;2.

Kay, J. E., and Coauthors, 2015: The Community Earth System Model (CESM) Large Ensemble project: A community resource for studying climate change in the presence of internal climate variability. Bull. Amer. Meteor. Soc., 96, 1333-1349, https://doi.org/10.1175/BAMS-D-13-00255.1.

Ke, C.-Q., A.-Q. Tao, and X. Jin, 2013: Variability in the ice phenology of Nam Co Lake in central Tibet from scanning multichannel microwave radiometer and special sensor microwave/ imager: 1978 to 2013. J. Appl. Remote Sens., 7, 073477, https:// doi.org/10.1117/1.JRS.7.073477.

Korhonen, J., 2006: Long-term changes in lake ice cover in Finland. Hydrol. Res., 37, 347-363, https://doi.org/10.2166/ nh.2006.019.

Kug, J.-S., J.-H. Jeong, Y.-S. Jang, B.-M. Kim, C. K. Folland, S.-K. Min, and S.-W. Son, 2015: Two distinct influences of Arctic warming on cold winters over North America and East Asia. Nat. Geosci., 8, 759-762, https://doi.org/10.1038/ngeo2517.

Latifovic, R., and D. Pouliot, 2007: Analysis of climate change impacts on lake ice phenology in Canada using the historical satellite data record. Remote Sens. Environ., 106, 492-507, https://doi.org/10.1016/j.rse.2006.09.015.

Li, F., H. Wang, and Y. Gao, 2015: The change in sea ice cover is responsible for non-uniform variation in winter temperature over East Asia. Atmos. Oceanic Sci. Lett., 8, 376-382, https:// doi.org/10.3878/AOSL20150039.

Li, H., H. Chen, H. Wang, J. Sun, and J. Ma, 2018: Can Barents Sea ice decline in spring enhance summer hot drought events over northeastern China? J. Climate, 31, 4705-4725, https://doi.org/ 10.1175/JCLI-D-17-0429.1.

Liu, J., J. A. Curry, H. Wang, M. Song, and R. M. Horton, 2012 : Impact of declining Arctic sea ice on winter snowfall. Proc. Natl. Acad. Sci. USA, 109, 4074-4079, https://doi.org/10.1073/ pnas.1114910109.

Liu, Y., H. Chen, H. Wang, and Y. Qiu, 2018: The impact of the NAO on the delayed break-up date of lake ice over the southern Tibetan Plateau. J. Climate, 31, 9073-9086, https:// doi.org/10.1175/JCLI-D-18-0197.1.

Livingstone, D. M., 1997: Break-up dates of Alpine lakes as proxy data for local and regional mean surface air temperatures. Climatic Change, 37, 407-439, https://doi.org/10.1023/A:1005371925924.

Mori, M., M. Watanabe, H. Shiogama, J. Inoue, and M. Kimoto, 2014: Robust Arctic sea-ice influence on the frequent Eurasian cold winters in past decades. Nat. Geosci., 7, 869-873, https:// doi.org/10.1038/ngeo2277.

Orsolini, Y. J., L. Zhang, D. Peters, K. Fraedrich, X. Zhu, A. Schneidereit, and B. Hurk, 2015: Extreme precipitation events over north China in August 2010 and their link to eastward-propagating wave-trains across Eurasia: Observations and monthly forecasting. Quart. J. Roy. Meteor. Soc., 141, 3097-3105, https://doi.org/10.1002/qj.2594.

Outten, S. D., and I. Esau, 2012: A link between Arctic sea ice and recent cooling trends over Eurasia. Climatic Change, 110, 1069-1075, https://doi.org/10.1007/s10584-011-0334-Z.
Qin, B., and Q. Huang, 1998: Evaluation of the climatic change impacts on the inland lake-A case study of Lake Qinghai, China. Climatic Change, 39, 695-714, https://doi.org/10.1023/ A:1005319616456.

Rangwala, I., J. R. Miller, and M. Xu, 2009: Warming in the Tibetan Plateau: Possible influences of the changes in surface water vapor. Geophys. Res. Lett., 36, L06703, https://doi.org/ 10.1029/2009GL037245.

Rayner, N. A., D. E. Parker, E. B. Horton, C. K. Folland, L. V. Alexander, D. P. Rowell, E. C. Kent, and A. Kaplan, 2003: Global analyses of sea surface temperature, sea ice, and night marine air temperature since the late nineteenth century. J. Geophys. Res., 108, 4407, https://doi.org/10.1029/2002JD002670.

Robertson, D. M., R. A. Ragotzkie, and J. J. Magnuson, 1992: Lake ice records used to detect historical and future climatic changes. Climatic Change, 21, 407-427, https://doi.org/10.1007/ BF00141379.

Sánchez-López, G., and Coauthors, 2015: The effects of the NAO on the ice phenology of Spanish alpine lakes. Climatic Change, 130, 101-113, https://doi.org/10.1007/s10584-015-1353-y.

Seviour, W. J. M., 2017: Weakening and shift of the Arctic stratospheric polar vortex: Internal variability or forced response? Geophys. Res. Lett., 44, 3365-3373, https://doi.org/10.1002/ 2017GL073071.

Shaman, J., and E. Tziperman, 2005: The effect of ENSO on Tibetan Plateau snow depth: A stationary wave teleconnection mechanism and implications for the South Asian monsoons. J. Climate, 18, 2067-2079, https://doi.org/10.1175/JCLI3391.1.

Smith, K. L., P. J. Kushner, and J. Cohen, 2011: The role of linear interference in northern annular mode variability associated with Eurasian snow cover extent. J. Climate, 24, 6185-6202, https://doi.org/10.1175/JCLI-D-11-00055.1.

Song, M., J. Liu, H. Liu, X. Ren, and X. Wang, 2012: Associations between the autumn Arctic sea ice and North American winter precipitation. Atmos. Ocean. Sci. Lett., 5, 212-218, https://doi.org/10.1080/16742834.2012.11446992.

Takaya, K., and H. Nakamura, 2001: A formulation of a phaseindependent wave-activity flux for stationary and migratory quasigeostrophic eddies on a zonally varying basic flow. J. Atmos. Sci., 58, 608-627, https://doi.org/10.1175/ 1520-0469(2001)058<0608:AFOAPI >2.0.CO;2.

, and - 2005: Geographical dependence of upper-level blocking formation associated with intraseasonal amplification of the Siberian high. J. Atmos. Sci., 62, 4441-4449, https:// doi.org/10.1175/JAS3628.1.

Todd, M. C., and A. W. Mackay, 2003: Large-scale climatic controls on Lake Baikal ice cover. J. Climate, 16, 3186-3199, https:// doi.org/10.1175/1520-0442(2003)016<3186:LCCOLB > 2.0.CO;2.

Vihma, T., 2014: Effects of Arctic sea ice decline on weather and climate: A review. Surv. Geophys., 35, 1175-1214, https:// doi.org/10.1007/s10712-014-9284-0.

Wang, H., H. Long, X. Li, and F. Yu, 2014: Evaluation of changes in ecological security in China's Qinghai Lake Basin from 2000 to 2013 and the relationship to land use and climate change. Environ. Earth Sci., 72, 341-354, https://doi.org/10.1007/ s12665-013-2955-1.

Wang, H.-J., and H. Chen, 2016: Understanding the recent trend of haze pollution in eastern China: Role of climate change. Atmos. Chem. Phys., 16, 4205-4211, https://doi.org/10.5194/ acp-16-4205-2016.

, and J. Sun, 2009: Variability of northeast China river breakup date. Adv. Atmos. Sci., 26, 701-706, https://doi.org/10.1007/ s00376-009-9035-1. 
H. Chen, and J. Liu, 2015: Arctic sea ice decline intensified haze pollution in eastern China. Atmos. Ocean. Sci. Lett., 8 , 1-9, https://doi.org/10.3878/AOSL20140081.

Wang, S., and J. Liu, 2016: Delving into the relationship between autumn Arctic sea ice and central-eastern Eurasian winter climate. Atmos. Ocean. Sci. Lett., 9, 366-374, https://doi.org/ 10.1080/16742834.2016.1207482.

Wang, Z., Y. Wu, J. Chang, X. Zhang, and D. Peng, 2017: Temporal and spatial variation of lake ice phenology and its influencing factors in the Tibetan Plateau (in Chinese). J. Beijing Univ. Technol., 43, 701-709.

Watanabe, M., 2004: Asian jet waveguide and a downstream extension of the North Atlantic Oscillation. J. Climate, 17, 46744691, https://doi.org/10.1175/JCLI-3228.1.

Xin, X., T. Zhou, and R. Yu, 2010: Increased Tibetan Plateau snow depth: An indicator of the connection between enhanced winter NAO and late-spring tropospheric cooling over East Asia. Adv. Atmos. Sci., 27, 788-794, https://doi.org/10.1007/ s00376-009-9071-x.

Xu, W., L. Ma, M. Ma, H. Zhang, and W. Yuan, 2017: Spatialtemporal variability of snow cover and depth in the QinghaiTibetan Plateau. J. Climate, 30, 1521-1533, https://doi.org/ 10.1175/JCLI-D-15-0732.1.

Yao, T., and Coauthors, 2012: Different glacier status with atmospheric circulations in Tibetan Plateau and surroundings. Nat. Climate Change, 2, 663-667, https://doi.org/10.1038/nclimate1580.

Yao, X., L. Li, J. Zhao, M. Sun, J. Li, P. Gong, and L. An, 2016: Spatial-temporal variations of lake ice phenology in the Hoh Xil region from 2000 to 2011. J. Geogr. Sci., 26, 70-82, https:// doi.org/10.1007/s11442-016-1255-6.

You, Q., S. Kang, N. Pepin, W.-A. Flügel, A. SanchezLorenzo, Y. Yan, and Y. Zhang, 2010: Climate warming and associated changes in atmospheric circulation in the eastern and central Tibetan Plateau from a homogenized dataset. Global Planet. Change, 72, 11-24, https://doi.org/10.1016/j. gloplacha.2010.04.003.

, G. Ren, K. Fraedrich, N. Pepin, Y. Yan, and L. Ma, 2011: Observed changes in snow depth and number of snow days in the eastern and central Tibetan Plateau. Climate Res., 46, 171-183, https://doi.org/10.3354/cr00985.

Zhang, G., H. Xie, S. Duan, M. Tian, and D. Yi, 2011: Water level variation of Lake Qinghai from satellite and in situ measurements under climate change. J. Appl. Remote Sens., 5, 053532 , https://doi.org/10.1117/1.3601363.

Zhang, R., R. Zhang, and Z. Zuo, 2017: Impact of Eurasian spring snow decrement on East Asian summer precipitation. J. Climate, 30, 3421-3437, https://doi.org/10.1175/JCLI-D-16-0214.1.

Zhang, Y., K. R. Sperber, and J. S. Boyle, 1997: Climatology and interannual variation of the East Asian winter monsoon: Results from the 1979-95 NCEP/NCAR reanalysis. Mon. Wea. Rev., 125, 2605-2619, https://doi.org/10.1175/ 1520-0493(1997)125<2605:CAIVOT > 2.0.CO;2.

Zhao, L., S. Y. S. Wang, and J. Meyer, 2017: Interdecadal climate variations controlling the water level of Lake Qinghai over the Tibetan Plateau. J. Hydrometeor., 18, 3013-3025, https://doi.org/ 10.1175/JHM-D-17-0071.1.

Zhu, L., J. Jin, X. Liu, L. Tian, and Q. Zhang, 2018: Simulations of the impact of lakes on local and regional climate over the Tibetan Plateau. Atmos.-Ocean, 56, 230-239, https://doi.org/ 10.1080/07055900.2017.1401524.

Zuo, J., H.-L. Ren, W. Li, and L. Wang, 2016: Interdecadal variations in the relationship between the winter North Atlantic Oscillation and temperature in south-central China. J. Climate, 29, 7477-7493, https://doi.org/10.1175/JCLI-D-15-0873.1. 